\title{
Cross-national insights into the relationship between wealth and wellbeing: a comparison between Australia, the United States of America and South Korea
}

\author{
SARANG KIM*, KERRY A SARGENT-COX*, DAVINA J. FRENCH*, HAL \\ KENDIG $\dagger$, KAARIN J ANSTEY* \\ * Centre for Mental Health Research, The Australian National University, Canberra, \\ ACT Australia \\ $\dagger$ Ageing, Work and Health Research Unit, Faculty of Health Sciences, The University \\ of Sydney, Sydney, NSW Australia
}

\section{ABSTRACT}

The positive relationship between wealth and wellbeing has received considerable attention over the last three decades. However, little is known about how the significance of wealth for the health and wellbeing of older adults may vary across societies. Furthermore, researchers tend to focus mainly on income rather than other aspects of financial resources even though older adults often rely on fixed income, particularly after retirement. Using data from the Household, Income and Labour Dynamics in Australia (HILDA) survey $(\mathrm{N}=1,431)$, the Health and Retirement Study (HRS, N=4,687), and the Korean Longitudinal Study of Ageing (KLoSA, N=5,447), this exploratory cross-national study examined the relationship between wealth satisfaction and objective wealth and wellbeing (measured as self-rated health and life satisfaction) among older Australians, Americans and Koreans (50+ years). Regression analyses showed that wealth satisfaction was associated with wellbeing over and above monetary wealth in all three countries. The relationship between monetary wealth and self-rated health was larger for the United States of America (USA) than Australian and Korean samples, while the additional contribution of wealth satisfaction to life satisfaction was larger for the Korean than the Australian and USA samples. These 
findings are discussed in terms of the cultural and economic differences between these countries, particularly as they affect older persons.

Key words: cross-national, Australia, USA, Korea, wealth satisfaction, subjective wellbeing, older adults, health 


\section{Introduction}

Wealth is strongly associated with both physical and mental health in the United States of America (USA) and other industrialised countries (Adams et al. 2003; Diener and Seligman 2004; Smith 1999). High-income individuals are generally healthier and live longer (Bethencourt and Galasso 2008) and this positive relationship extends to older adults (Kahn and Fazio 2005; Keith 1993; Kim 2006). Longitudinal studies have demonstrated that this relationship is probably bi-directional, with wealth protecting against illness and ill-health depleting wealth (Cai 2009; Michaud and van Soest 2008). A similar relationship has been found in East-Asian countries such as South Korea; individuals with a high socioeconomic status (SES) have better health states (Lee et al. 2005; Lee and Jeon 2005; Park, Jung and Lee 2009). However, these studies were conducted at the country level and the relationship between wealth and health has not been systematically compared between Asian and Western countries.

Individuals' financial resources have been conceptualised in a variety of ways, but studies have often focussed on income (Danigelis and McIntosh 2001; Hsieh 2001; La Barbera and Gürhan 1997). For older people, sources of income are mostly fixed in the form of social security and private pensions (Keith 1993). Elders also have different spending patterns compared to young adults; for example, they may have fewer major expenses such as loan repayments, whereas their health care expenses may be higher. Measures of assets or net worth have therefore been used to quantify financial resources for older adults and may provide additional information in this instance.

Objective measures such as income and assets might not, however, fully explain the association between financial resources and health for older adults. The availability of support from government and/or family in different countries is also pertinent when 
making cross-national comparisons; objective measures of wealth may have different meanings where, for example, public health services differ and wealth may play a more or less significant role in accessing health care services. Perceptions of wealth are contextual and subjective, but are associated with increased mortality (Szanton et al. 2008) and poorer self-rated health (Kahn and Pearlin 2006) even after controlling for absolute income. The same level of income or net worth may be perceived as sufficient for one person but result in financial strain for another due to different life situations or circumstances (Kahn and Fazio 2005; Szanton et al. 2008) and this may be independently associated with health. Inclusion of a measure of satisfaction with or perceived adequacy of financial resources is likely to improve our understanding of the health/wealth relationship.

The current study therefore investigates the relationship between wealth and self-rated health among older Australians, Americans and South Koreans in three nationally representative samples, using both objective and subjective measures of household wealth.

\section{Background}

In Korea adult children support their elderly parents in later life for normative and practical reasons (Kim and Choe 1992; Yoon and Cha 1999) whereas Australian elders are more likely to be self sufficient or recipients of government support. Differences in subjective ratings of wealth satisfaction, and their relationship with objective wealth, might therefore be expected between countries but research into the association between wealth and wellbeing in Asian countries has only considered measures of objective wealth to date. 
In studies of USA samples gender has also been shown to be an important component of the health/wealth relationship. Women in middle and old age have lower median asset levels (Denton and Boos 2007) and less favourable pension arrangements than men (Shuey and O'Rand 2006). This may be due to older women being less likely to be married than men, as a result of their greater likelihood of being widowed (Keith 1993; Liang, Kahana and Doherty 1980, Mendes De Leon, Rapp and Kasl 1994). Being without a spouse has also been found to significantly increase the wealth depleting impact of poor health (Kim 2006). Studies that have examined gender differences from a cross-national perspective are still lacking. A cross-national comparison allows examination of the effect of differences in gender roles as well as work place opportunities and policies on the relationship between health and wealth.

The current paper considers the influence of societal context on these relationships, which to date have been explored primarily in western countries, especially the USA and European countries. Australia and United States are important to compare because studies examining the relationship between wealth and health have been predominantly conducted using USA samples. These nations have similar levels on the human development index, (HDI) which describes national wellbeing based on average life expectancy, education levels and standard of living (United Nations Development Programme, 2009). South Korea (hereafter Korea) is also similar to the USA and Australia in terms of its HDI but it has very different social values and structures to those of the USA and Australia. Since the 1960s Korea has achieved an incredible record of growth and global integration to become a high-tech industrialized economy (Choi 2009), and has grown more rapidly than the USA (Kim 2008). Consequently, economic changes occurred more rapidly than societal changes and 
therefore Koreans, especially older Koreans, may still hold traditional collectivist and Confucian values in life, including traditional beliefs about gender roles. This is reflected in the fact that, despite their similar HDI rankings, Korea is ranked $61^{\text {st }}$ among 109 countries in gender empowerment compared to Australia's $7^{\text {th }}$ and the USA $18^{\text {th }}$ (UNDP 2009).

We expect to find a relationship between health and wealth in all three countries and to find that satisfaction with wealth accounts for additional variance in self-rated health beyond objective measures. Our analyses will allow us to compare the magnitude of these effects across countries. Since gender empowerment differs markedly, the relationships between health, wealth and satisfaction for men and women are also expected to differ between these countries.

In contrast with health outcomes, there is a large body of research on crossnational differences in the relationship between financial status and subjective wellbeing (SWB), conceptualised as happiness or life satisfaction. These studies suggest that wealth is related to SWB at the national level, with more affluent countries being on average happier, but that this relationship is curvilinear with less effect at higher levels of affluence (Dolan, Peasgood and White 2008). Within countries wealth and income are more strongly associated with SWB where average incomes are low and the availability of resources to meet basic needs is therefore more directly relevant (Diener, Oishi and Lucas 2003). Expectations and aspirations are also important for SWB (Dolan et al. 2008); satisfaction with wealth may reflect these and therefore be a component of life satisfaction that is at least partially independent of objective income and wealth. 
Studies investigating SWB have typically employed student or national samples with little evidence being available about the relationship between economic variables and life satisfaction among older individuals, especially in Asia. Despite its similar HDI ranking, per capita GDP is lower in Korea than in the USA and Australia, and there is evidence that elders may be especially disadvantaged (Yun 2010). We therefore expect to find a relationship between wealth satisfaction and life satisfaction that is independent of objective income and wealth in all three countries, and that this relationship will be somewhat larger in Korea.

\section{Method}

\section{Participants and Sampling}

All three samples were drawn from nationally representative surveys conducted in 2006 and included only community dwelling adults. Only those aged 50 years and older were selected for analysis to match the age range of the USA sample.

The Australian sample was drawn from the Household, Income and Labour Dynamics in Australia (HILDA) survey, a household-based panel study, which began in 2001. The interviews have been conducted annually with household members aged 15 and over to collect information about economic and subjective wellbeing, labour market dynamics and family dynamics. The current study analysed a total of 1,431 individuals from wave 6 who had provided all of the required responses.

The American sample was drawn from wave 8 of the Health and Retirement Study (HRS). HRS is a biennial, nationally representative longitudinal survey of USA adults aged 50 and over and their spouses or partners. It covers a wide range of measures such as physical and mental health, insurance coverage, financial status, 
family support systems, labour market status, and retirement planning. The final sample included 4,687 respondents who had completed all of the required questions.

The first wave of the Korean Longitudinal Study of Ageing (KLoSA) provided the Korean sample. KLoSA covers the middle and old-aged population nationwide excluding people in Jeju Island. KLoSA was designed to be comparable with similar panel studies in other countries (e.g., the HRS in USA) that can provide the basis for policy-making academic studies. In the first wave, a total of 10,254 respondents were surveyed; 5,447 were within the age range and had provided sufficient data for inclusion in this paper.

All analyses used the relevant population weights to adjust for the complex sampling design (stratification and clustering) of each study.

\section{Dependent variables}

For self-rated health, all three samples used the same item, asking 'would you say your health is...' with a five-point Likert scale ranging from 1 (poor) to 5 (excellent). The use of all five scale points for this dependent variable would have resulted in small cell sizes since the distribution of self-rated health varied markedly across countries. In order to avoid this and to obtain distributions that were as similar as possible between countries, self-rated health was dichotomised into 'good' (excellent, very good and good) and 'poor' (poor and fair) for logistic regression analysis.

Life satisfaction was measured with a question 'how satisfied are you with your life?' on a scale of 0 to 10 for HILDA and 'in general, how satisfied are you with your quality of life when compared to others in your age' on a scale of 0 to 100 for KLoSA. For both of these measures a higher score indicates greater life satisfaction. For HRS, life satisfaction was measured with 'I am satisfied with my life' with responses 
measured on a six-point Likert scale from 1 (strongly disagree) to 6 (strongly agree). The Korean variable was divided by 10 to match the eleven-point scale of the Australian variable and the USA variable similarly transformed so that 'strongly disagree' was equal to 0 and 'strongly agree' was equal to 10 . Values in Table 1 are reported on this eleven-point scale.

\section{Independent variables}

Income was assessed as total household income, which has been equivalised, using the International Experts' Scale, i.e. income divided by the square root of household size (Buhmann et al. 1988). Income for Australians and Koreans was further adjusted for Purchasing Power Parity (PPP) to be comparable with the USA income. Net worth was calculated by subtracting debts from total assets, which was also equivalised. Similar to income, wealth for the Australian and Korean samples was adjusted for PPP. To facilitate comparison of the odds ratios for these variables with the wealth satisfaction variable they were entered into regression analyses as deciles.

For wealth satisfaction, HILDA asked participants how satisfied or dissatisfied they were with their financial situation on a scale of 0 to 10 , with a higher number indicating greater satisfaction. In the U.S sample, a question 'How satisfied are you with (your/your family's) present financial situation?' was given to participants. Responses ranged from 1 (not at all satisfied) to 5 (completely satisfied). In the Korean sample, a similar question to HILDA was used with the exception of the scale being between 0 (completely dissatisfied) to 100 (completely satisfied). Again the Korean variable was divided by 10 to match the eleven-point scale of the Australian variable and the USA variable similarly transformed so that 'not at all satisfied' was equal to 0 
and 'completely satisfied' was equal to 10 . Values in Table 1 are reported on this eleven-point scale.

\section{Covariates}

Age groups of ten year cohorts were used as a covariate. Respondents' marital status was included in all surveys but different response options were provided. The harmonised variable of partner status therefore had only two categories of currently partnered versus not partnered. Education attainment was also collected in all three surveys but again response categories differed. The harmonised variable had three categories that reflected (1) primary school or less; (2) some/finished high school; and (3) post-secondary education. The employment status variable was harmonised into five categories indicating (1) working full time, (2) working part time, (3) completely retired, (4) unemployed and (5) not in the labour force.

For medical conditions, in the USA and Korean samples, seven items asked respondents whether they were ever told by a doctor that they have: diabetes; cancer (excluding skin cancer); a lung condition (chronic bronchitis, emphysema); high blood pressure or hypertension; a heart attack, coronary heart disease, angina, congestive heart failure, or other heart problem; stroke; and arthritis or rheumatism. The Australian sample on the other hand was asked whether they had any long term health condition, impairment or disability that restricts them in their everyday activities, and has lasted or is likely to last for 6 months or more. These included long term effects as a result of a head injury, stroke or other brain damage; a long term condition or ailment which is still restrictive even though it is being treated; and any other long term condition such as arthritis, asthma, heart disease, Alzheimer's disease, dementia, etc. Since the conditions covered differed between countries, this information was reduced to a binary variable, 
entered as 1 if the respondents' answer for any of these items was yes and 0 if they reported none of medical conditions.

Questions about difficulty with bathing and dressing were included in all three surveys and were used to represent respondents' disability level. HILDA had one item on bathing and dressing, HRS had two items on dressing and bathing or showering, and KLoSA had three items on dressing, washing face/hair/brushing teeth and bathing/showering. These were harmonised across samples as 0 (no difficulty) or 1 (difficulty) with self-care.

Analysis

Logistic regression was used to examine the association of income, net worth and wealth satisfaction with self-rated health and hierarchical linear multiple regression was used to examine their association with life satisfaction. These analyses were conducted separately for each country, in order to show more clearly the influence of the different national contexts, and for men and women in each country to examine the relative importance of gender influences.

Since income and net worth shared variance they were entered together; the overall test of model 1 indicates their combined effect. Wealth satisfaction was then added (model 2) to assess its independent contribution. Age, partner status, education, employment status, medical conditions, and disability were then entered for adjustment (model 3). Since these variables are related to both health and wealth it is of interest to examine whether the observed relationships remain when these adjustments are made, but their disappearance would not necessarily devalue the findings since individuals do not in fact exist independently of their life circumstances. The coefficients for these 
control variables are not reported in the tables although the effect of their inclusion on the total variance explained is provided.

\section{Results}

\section{Characteristics of the sample}

Table 1 shows the characteristics of the Australian, USA and Korean samples. The USA sample was older and had a lower proportion of men than Australian and Korean samples. Koreans were significantly more likely to be partnered than Australians and Americans; in particular more than 90 per cent of Korean men were partnered. Educational attainment was significantly lower in the Korean sample, particularly in Korean women. In employment status, Koreans were significantly more likely to describe themselves as not in the labour force, and less likely to be completely retired, than Australians and Americans.

Koreans, especially Korean women, were more likely to report their health as poor than Americans and Australians. The largest proportion of Australians reported their health as fair and the largest proportion of Americans reported their health as good. Despite lower levels of self-rated health, Koreans were least likely to report having any medical conditions or disability. The USA sample showed an extremely high proportion of people having medical conditions and the Australian sample had the highest proportion of people reporting disability. When transformed to equivalent scales, both wealth satisfaction and life satisfaction were highest for Australians followed by Americans and Koreans.

In terms of objective wealth, the USA sample had the highest mean income and the Australian sample had the highest mean net worth, after correction for purchasing 
power parity. The USA sample however had very large standard deviations for mean income and net worth.

$<$ Insert Table 1 about here $>$

\section{Wealth and self-rated health}

The odd ratios of good self-rated health can be found in Table 2. The association of income and net worth with self-rated health (model 1) was significant in all analyses, with 5.3-14 per cent variance explained; this effect was largest in the USA samples. Both variables were independently associated with health for all groups except Australian women where only net worth was significant. The addition of wealth satisfaction (model 2) added between 0.1 per cent (USA men) and 8.4 per cent (Korean men) variance and was significant for all groups except USA men. The odds ratios for wealth satisfaction were considerably larger in Korea than elsewhere. After adjusting for age, education, partner status, employment status, medical conditions, and disability, none of the wealth variables remained significant for the Australian men. For the female samples and the Korean men the association of wealth satisfaction with self-rated health remained, with the sociodemographic variables explaining a further 12.3-20.9 per cent variance.

$<$ Insert Table 2 about here $>$

Wealth and satisfaction with life 
A set of multiple linear regression analyses were conducted with life satisfaction as the dependent variable, see Table 3. Income and net worth (model 1) showed a significant association with life satisfaction in all groups except Australian men; however in the Western samples this effect explained less than 5 per cent variance. The effect was somewhat larger in the Korean groups, with 12-13 per cent variance explained. Wealth satisfaction (model 2) shared an independent 8.4-29.3 per cent variance with life satisfaction and showed similar relationships for men and women; regression coefficients exceeded 0.3 in the Western countries and 0.5 in Korea. After adjusting for age, education, partner status, employment status, medical conditions, and disability these coefficients changed only slightly.

$<$ Insert Table 3 about here $>$

\section{Discussion}

In this cross-national study, we explored associations between different measures of wealth and wellbeing in older adults in Australia, the USA and South Korea. The findings suggest that older individuals' satisfaction with their wealth is associated with wellbeing over and above the objective level of their income and assets. This pattern was found across all three countries for life satisfaction and in four of the six analyses for self-rated health. Although the following discussion highlights the differences that were observed between analyses, it should be noted that wealth satisfaction was commonly associated with wellbeing over and above the effect of objective wealth in the samples that we investigated. This supports previous findings that objective income measures alone are not adequate indicators of socioeconomic status in older adults (Sun 
et al. 2009) and that the relationship between wealth satisfaction and wellbeing is distinct from objective economic status (Myers 2000).

The association between monetary wealth and self-rated health was largest for the American samples, and the additional effect of wealth satisfaction was smaller for Americans than in the other countries. This could be due to differences in health insurance cover in these countries. In the USA, the health care system relies heavily on the private insurance sector. Private health insurers cover about 35 per cent of national health spending in the USA and out of pocket payment by patients is about 19 per cent (Reinhardt 2001). The remainder is covered by government programmes, including the federal Medicare programme for persons aged 65 and over. Although Medicare helps to cover in-patient care and out-patient services, about 12 million elderly Americans do not have cover for expenses such as prescription drugs, which are excluded from Medicare (Reinhardt 2001). In addition it should be noted that our sample was selected from those aged 50 years and over, thereby including a proportion of people not eligible for Medicare. Therefore, real financial resources may be more closely associated with good health in the USA sample than in Australia and Korea because they confer the opportunity for adequate health insurance and direct purchase of improved health care.

In Korea the association of wealth satisfaction with self-rated health, after taking account of objective wealth, was large and similar for men and women. In the two Western countries however, wealth satisfaction showed this unique association with self-rated health only among women; the effect was not significant for USA men and in Australian men it was lost after adjustment for age, education, partner status, employment status, medical conditions and disability. 
The relationship between wealth satisfaction and life satisfaction does not appear to differ between men and women in any of the countries we studied. Wealth satisfaction did show a stronger association with life satisfaction for Koreans than Australian and Americans. This is consistent with our prediction, which was based on the likelihood of higher levels of financial strain among Korean elders. The rapidly changing economic situation in Korea has been matched by changes in cultural values and support surrounding retired older adults in Korea (Jang et al. 2004). Hyo, which is translated as filial duty or filial piety and refers to care given by children to their parents, is one of the most essential elements for the practice of benevolence, which is a core concept of Confucian philosophy (Koh and Koh 2008). In accordance with Confucian values, retired parents have traditionally been supported by their adult children once they do not have a reliable income after leaving the workforce (Yun 2010). However, due to recent economic changes and westernisation these Confucian principles are losing dominance in Korean society. Contrary to the Confucian ideal, more older adults are remaining in the labour force after retirement age (Yun 2010). In 2005, approximately 30 per cent of Koreans aged 65 years and above participated in labour markets, while only 70 per cent of Koreans in the 25 to 29 year old age range were economically active. These changes in the labour market and cultural values in Korea may lead to older Koreans being more wary regarding accumulated wealth and selfsufficiency and therefore, wealth satisfaction is a larger contributor to their life satisfaction. Future studies would benefit from examining the roles that societal and family structures play in determining satisfaction among Koreans. This is of particular importance since, if older Koreans do still live with their adult children, the construct of household wealth may have a different meaning for them. 
The main strength of the current research is that we used large nationally representative datasets which are comparable. The present study also contributes to the limited research in ageing and health in a cross-national context as studies examining cross-cultural and national differences in the health of older people, especially those examining non-Western countries, are rare. This study can be useful because understanding the relationship between wealth and wellbeing is important for policies aimed at improving welfare, health, and wellbeing (Deaton and Paxson 1998).

When interpreting the results of this study, there are several limitations which should be noted. Firstly, all data analyses were cross-sectional, consequently only the association, not the causal relationship, between wealth and wellbeing can be inferred. Establishing causality of the relationship is challenging as three types of explanations can exist: causal effects from health to wealth, causal effects from wealth to health, and unobserved individual heterogeneity driving health and wealth in similar ways (Michaud and van Soest 2008). Causality was not however the main focus of the current paper. Rather, we were interested in examining cross-national differences in the relationship between wealth and wellbeing.

Secondly, the measures used in the study differed slightly across countries; in particular the scale of the satisfaction variables allowed differing degrees of precision in responding. We were able to explain less variance in life satisfaction in the USA sample, which may be due to the fact that although the responses were transformed to the same scale, they encompassed a smaller set of response options from the USA survey. As in much cross-cultural research, comparability of meaning can only be approximated, due to language differences as well as cultural effects. Even for variables with the same scales, for example self-rated health, people in different countries may use different 
thresholds for responding. We reduced the magnitude of this effect by collapsing the scale to minimise differences in the use of extreme options, but future studies can further reduce this bias by using 'vignette' questions, which allow the researcher to calibrate individuals' self reported scales to a common scale (Kapteyn, Smith and von Soest 2007). The primary data for Australia and Korea, however, did not allow us to use this approach.

This study suggests several directions for future research. Firstly, the current study is restricted to Australia, the USA, and South Korea; comparing another Asian country such as Japan, which has higher wealth levels achieved decades earlier than in Korea, could give a further understanding of the factors underlying the differences observed here. Secondly, longitudinal studies would be useful in examining how changes in wealth (both perceived and objective) are associated with changes in selfrated health and satisfaction with life. Finally, we suggest that more in-depth qualitative investigations could shed light on the social determinants and meanings underlying the findings.

In conclusion, this study has supported the positive but modest relationship between wealth and wellbeing that has received considerable attention over the last three decades (Bowling 1995; Keith 1993; Liang, Kahana and Doherty 1980; Schieman, Van Gundy and Taylor 2001). Moreover, our study suggests that perceived satisfaction with wealth is associated with wellbeing over and above absolute income and net worth. Comparing three countries allows us to suggest that this relationship can be found across nationalities with different cultural and policy contexts, at least across developed countries. Future studies on possible factors mediating the relationship between perceptions of wealth and wellbeing are strongly suggested. 


\section{Acknowledgements}

This paper uses unit record data from the Household, Income, and Labour Dynamics in Australia (HILDA) Survey. The HILDA Project was initiated and is funded by the Australian Government Department of Family, Housing, Community Services and Indigenous Affairs (FaHCSIA) and is managed by the Melbourne Institute of Applied Economic and Social Research (MIAESR). The findings and views reported in this paper, however, are those of the authors and should not be attributed to either FaHCSIA or the MIAESR.

Data from wave 8 of the Health and Retirement Study are used with permission. HRS is sponsored by the National Institute of Aging (grant number NIA U01AG009740) and conducted by the University of Michigan.

Data from KLoSA are used with permission. KLoSA is conducted by the Korean Labor Institute and funded by the Korean Ministry of Labor through the Employment Insurance Fund.

Sarang Kim was supported by ARC/NHMRC Research Network in Ageing Well, Davina French by NHMRC Project Grant No. 410215 and Kaarin Anstey by NHMRC Research Fellowship No. 366756. 


\section{References}

Adams, P., Hurd, M. D., McFadden, D., Merrill, A. and Ribeiro, T. 2003. Healthy, wealth, and wise? Tests for direct causal paths between health and socioeconomic status. Journal of Econometrics, 112, 1, 3-56.

Bethencourt, C., and Galasso, V. 2008. Political complements in the welfare state: Health care and social security. Journal of Public Economics, 92, 3-4, 609-32.

Bowling, A. 1995. What things are important in people's lives? A survey of the public's judgements to inform scales of health related quality of life. Social Science \& Medicine, 41, 10, 1447-62.

Buhmann, B., Rainwater, L., Schmaus, G. and Smeeding, T. M. 1988. Equivalence scales, well-being, inequality and poverty: Sensitivity estimates across ten countries, using the Luxembourg Income Study (LIS) database. Review of Income and Wealth, 34, $2,115-42$

Cai, L., 2009. Be wealthy to stay healthy: An analysis of older Australians using the HILDA survey. Journal of Sociology, 45, 1, 55-70.

Choi, A. 2009. Sequential educational expansion, equality, and growth in the Republic of Korea. KEDI Journal of Educational Policy, 6, 2, 21-47.

Danigelis, N. L. and McIntosh, B. R. 2001. Gender's effect on the relationships linking older Americans' resources and financial satisfaction. Research on Aging, 23, 4, 410-28. Deaton, A. S. and Paxson, C. H. 1998. Aging and inequality in income and health. The American Economic Review, 88, 2, 248-53.

Denton, M. and Boos, L. 2007. The gender wealth gap: Structural and material constraints and implications for late life. Journal of Women \& Aging, 19, 3-4, 105-20. 
Diener, E., Oishi, S. and Lucas, R.E., 2003. Personality, culture and subjective wellbeing: Emotional and cognitive evaluations of life. Annual Review of Psychology, 54, 403-25.

Diener, E. and Seligman, M. E. P. 2004. Beyond money: Toward an economy of wellbeing. Psychological Science in the Public Interest, 5, 1, 1-31.

Dolan, P., Peasgood, T. and White, M. 2008. Do we really know what makes us happy? A review of the economic literature on the factors associated with subjective well-being. Journal of Economic Psychology, 29, 1, 94-122.

Hsieh, C. M. 2001. Correlates of financial satisfaction. International Journal of Aging \& Human Development, 52, 2, 135-53.

Jang, Y., Poon, L. W., Kim, S.Y. and Shin, B. K. 2004. Self-perception of ageing and health among older adults in Korea. Journal of Aging Studies, 18, 4, 485-96.

Kahn, J. R. and Fazio, E. M. 2005. Economic status over the life course and racial disparities in health. Journal of Gerontology, 60B, Special Issue II, 76-84.

Kahn, J. R. and Pearlin, L. I. 2006. Financial strain over the life course and health among older adults. Journal of Health and Social Behavior, 47, 1, 17-31.

Kapteyn, A., Smith, J. P. and van Soest, A. 2007. Vignettes and self-reports of work disability in the Unites States and the Netherlands. The American Economic Review, 97, $1,461-73$.

Keith, V. M. 1993. Gender, financial strain, and psychological distress among older adults. Research on Aging, 15, 2, 123-47.

Kim, B. W. 2008. Future of economic growth for South Korea. Asian Economic Journal, 22, 4, 397-410. 
Kim, H. 2006. Older women's health and its impact on wealth. Journal of Women and Aging, 18, 1, 75-91.

Kim, I. K. and Choe, E. H. 1992. Support exchange patterns of the elderly in Korea. Asia-Pacific Population Journal, 7, 3, 89-104.

Koh, E-K. and Koh, C-K. 2008. Caring for older adults: The parables in Confucian texts. Nursing Science Quarterly, 21, 4, 365-68.

La Barbera, P. A. and Gürhan, Z. 1997. The role of materialism, religiosity, and demographics in subjective well-being. Psychology and Marketing, 14, 1, 71-97. Lee, S-G. and Jeon, S-Y. 2005. The relations of socioeconomic status to health status, health behaviours in the elderly. Journal of Preventive Medicine and Public Health, 38, 2, 154-62. (Korean)

Lee, H. Y., Kim, S. A., Lee, H. J. and Jung, S. H. 2005. The relationship between socioeconomic factors and self-rated health among older people. Korean Journal of Health Policy \& Administration, 15, 2, 70-83. (Korean)

Liang, J., Kahana, E. and Doherty, E. 1980. Financial well-being among the aged: A further elaboration. Journal of Gerontology, 35, 3, 409-20.

Mendes De Leon, C. R., Rapp, S. S. and Kasl, S. V. 1994. Financial strain and symptoms of depression in a community sample of elderly men and women: A longitudinal study. Journal of Aging Health, 6, 4, 448-68.

Michaud, P-C. and van Soest, A. 2008. Health and wealth of elderly couples: Causality tests using dynamic panel data models. Journal of Health Economics, 27, 13, 1312-25. Myers, D. G. 2000. The funds, friends and faith of happy people. American Psychologist, 55, 1, 56-67. 
Park, B-H., Jung, M. and Lee, T-J. 2009. Associations of income and wealth with health status in the Korean elderly. Journal of Preventive Medicine and Public Health, 42, 5, $275-82$.

Reinhardt, U. E. 2001. The United States health-care system: Recent history and prospects. Paper presented to the International Symposium on Health Care Policy, Washington, D.C., October 9-11, 2001.

Schieman, S., Van Gundy, K. and Taylor, J. 2001. Status, role, and resource explanations for age patterns in psychological distress. Journal of Health and Social Behavior, 42, 1, 80-96.

Shuey, K. M. and O'Rand, A. M. 2006. Changing demographics and new pension risks. Research on Aging, 28, 3, 317-40.

Smith, J. P. 1999. Healthy bodies and thick wallets: The dual relation between health and economic status. Journal of Economic Perspectives, 13, 2, 145-66.

Sun, F., Hilgeman, M. M., Durkin, D. W., Allen, R. S. and Burgio, L. D. 2009. Perceived income inadequacy as a predictor of psychological distress in Alzheimer's caregivers. Psychology and Aging, 24, 1, 177-83.

Szanton, S. L., Allen, J. K., Thorpe, R. J., Seeman, T., Bandeen-Roche, K. and Fried, L. P. 2008. Effect of financial strain on mortality in community-dwelling older women. Journal of Gerontology Series B - Psychological Sciences and Social Sciences, 63, 6, S369-S374.

United Nations Development Programme [UNDP] 2009. Human Development Report 2009; Overcoming barriers: Human Mobility and Development. Basingstoke, Hampshire: Palgrave Macmillan. 
Yoon, H. and Cha, H-B. 1999. Future issues for family care of the elderly in Korea. Hallym International Journal of Aging, 1, 1, 78-86.

Yun, J-W. 2010. The myth of Confucian capitalism in South Korea: Overworked elderly and underworked youth, Pacific Affairs, 83, 2, 237-29. 
Address for correspondence:

Dr. Davina French

Centre for Mental Health Research

Australian National University

Canberra, 0200, ACT, Australia

Email: Davina.French@anu.edu.au 
Table 1. Sample descriptives for Australian (HILDA), American (HRS) and Korean (KLoSA) men and women

\begin{tabular}{|c|c|c|c|c|c|c|c|c|c|}
\hline \multirow[t]{2}{*}{ Variable } & \multicolumn{3}{|c|}{ Australia } & \multicolumn{3}{|c|}{$\begin{array}{c}\text { USA } \\
\text { Percentages }\end{array}$} & \multicolumn{3}{|c|}{ Korea } \\
\hline & Male (46.3) & Female (53.7) & Total & Male (37.1) & Female (62.9) & Total & Male (40.8) & Female (59.2) & Total \\
\hline \multicolumn{10}{|l|}{ Age* } \\
\hline $50-59$ & 29.7 & 31.6 & 30.8 & 16.7 & 18.5 & 17.9 & 32.4 & 35.3 & 34.2 \\
\hline $60-69$ & 32.3 & 28.4 & 30.2 & 31.1 & 32.3 & 31.8 & 37.0 & 32.9 & 34.6 \\
\hline $70-79$ & 27.2 & 24.6 & 25.8 & 33.6 & 29.6 & 31.1 & 24.1 & 22.7 & 23.3 \\
\hline $80+$ & 10.9 & 15.4 & 13.3 & 18.6 & 19.6 & 19.2 & 6.5 & 9.1 & 8.0 \\
\hline Mean (SD) & $66.3(9.9)$ & $66.8(10.8)$ & $66.6(10.4)$ & $70.2(9.8)$ & $69.9(10.4)$ & $70.0(10.2)$ & $64.8(9.2)$ & $65.0(10.2)$ & $64.9(9.8)$ \\
\hline \multicolumn{10}{|l|}{ Educational level* } \\
\hline Some/finished primary school & 6.6 & 6.6 & 6.6 & 5.1 & 4.3 & 4.6 & 35.0 & 64.4 & 52.4 \\
\hline Some/finished high school & 38.6 & 60.0 & 50.1 & 51.9 & 57.9 & 55.7 & 48.6 & 32.0 & 38.7 \\
\hline Post-secondary & 54.8 & 33.3 & 43.3 & 43.0 & 37.8 & 39.7 & 16.4 & 3.6 & 8.8 \\
\hline \multicolumn{10}{|l|}{ Partner status* } \\
\hline Partnered & 70.3 & 47.5 & 58.1 & 81.9 & 55.0 & 65.0 & 91.6 & 65.1 & 75.9 \\
\hline \multicolumn{10}{|l|}{ Self-rated health* } \\
\hline Poor & 13.0 & 13.4 & 13.2 & 9.5 & 9.1 & 9.2 & 23.4 & 34.1 & 29.7 \\
\hline Fair & 35.8 & 40.0 & 38.0 & 27.0 & 24.9 & 25.7 & 27.3 & 30.2 & 29.0 \\
\hline Good & 34.7 & 33.5 & 34.0 & 34.2 & 33.5 & 33.7 & 37.5 & 28.0 & 31.9 \\
\hline Very Good & 15.2 & 11.9 & 13.4 & 23.8 & 26.8 & 25.7 & 9.9 & 6.4 & 7.8 \\
\hline Excellent & 1.4 & 1.3 & 1.3 & 5.6 & 5.9 & 5.8 & 2.0 & 1.3 & 1.6 \\
\hline \multicolumn{10}{|l|}{ Medical conditions* } \\
\hline Some medical conditions & 60.5 & 69.1 & 65.1 & 93.0 & 92.9 & 92.9 & 47.3 & 56.3 & 52.6 \\
\hline \multicolumn{10}{|l|}{ Bathing and Dressing* } \\
\hline \multirow{2}{*}{\multicolumn{10}{|c|}{ Employment status* }} \\
\hline & & & & & & & & & \\
\hline Full time & 18.4 & 8.9 & 13.3 & 20.0 & 13.8 & 16.1 & 30.0 & 7.5 & 16.7 \\
\hline Part time/Partly retired & 9.4 & 10.7 & 10.1 & 13.6 & 14.0 & 13.9 & 3.9 & 2.1 & 2.9 \\
\hline Completely retired & 67.3 & 75.1 & 71.5 & 60.7 & 51.7 & 55.0 & 39.6 & 17.8 & 26.7 \\
\hline Unemployed & 0.9 & 1.2 & 1.1 & 0.5 & 0.7 & 0.6 & 9.6 & 3.7 & 6.1 \\
\hline Not in labour force & 4.1 & 4.2 & 4.1 & 5.2 & 19.7 & 14.4 & 16.9 & 68.9 & 47.6 \\
\hline \multicolumn{10}{|l|}{ Satisfaction with +} \\
\hline Wealth - Mean $(\mathrm{SD})^{*}$ & $6.68(2.30)$ & $6.50(2.47)$ & $6.58(2.39)$ & $5.55(2.62)$ & $5.42(2.77)$ & $5.47(2.71)$ & $4.91(2.41)$ & $4.62(2.40)$ & $4.74(2.41)$ \\
\hline Life - Mean (SD)* & $7.89(1.69)$ & $7.83(1.79)$ & $7.86(1.75)$ & $7.16(2.80)$ & $7.07(2.92)$ & $7.10(2.88)$ & $6.19(2.08)$ & $5.99(2.19)$ & $6.08(2.15)$ \\
\hline \multicolumn{10}{|l|}{ Objective wealth } \\
\hline \multirow[t]{2}{*}{ Income (SD)* } & 27,010 & 21,757 & 24,191 & 44,991 & 36,840 & 39,864 & 14,521 & 14,521 & 14,302 \\
\hline & $(29,797)$ & $(19,277)$ & $(24,844)$ & $(133,455)$ & $(104,937)$ & $(116,389)$ & $(18,196)$ & $(18,494)$ & $(18,372)$ \\
\hline \multirow[t]{3}{*}{ Net worth (SD)* } & 403,155 & 334,939 & 366,544 & 395,447 & 320,869 & 348,539 & 146,424 & 138,314 & 141,625 \\
\hline & $(674,418)$ & $(593,170)$ & $(632,803)$ & $(1578,715)$ & $(1236,134)$ & $(1373,556)$ & $(278,324)$ & $(267,577)$ & $(272,020)$ \\
\hline & & 1,431 & & & 4,687 & & & 5,447 & \\
\hline
\end{tabular}

+ These means are matched across three countries (on a scale of 0 to 10 ). 


\begin{tabular}{|c|c|c|c|c|c|c|}
\hline & \multicolumn{3}{|c|}{ Australian Men } & \multicolumn{3}{|c|}{ Australian Women } \\
\hline & Model 1 & Model 2 & Model $3^{b}$ & Model 1 & Model 2 & Model $3^{b}$ \\
\hline Income & $1.14(1.06-1.23)^{* *}$ & $1.14(1.06-1.23)^{* *}$ & $1.08(0.98-1.19)$ & $1.04(0.98-1.11)$ & $1.04(0.98-1.11)$ & $0.96(0.89-1.04)$ \\
\hline Net Worth & $1.09(1.01-1.18)^{*}$ & $1.06(0.98-1.15)$ & $1.04(0.95-1.13)$ & $1.13(1.06-1.21)^{* *}$ & $1.08(1.01-1.16)^{*}$ & $1.07(1.00-1.14)$ \\
\hline Wealth Satisfaction & & $1.10(1.01-1.20)^{*}$ & $1.08(0.98-1.19)$ & & $1.18(1.10-1.27)^{* * *}$ & $1.30(1.19-1.42)^{* * *}$ \\
\hline Nagelkerke's R ${ }^{2}$ & .084 & .146 & .354 & .053 & .095 & .264 \\
\hline $\mathrm{R}^{2} \Delta$ & & .062 & .208 & & .042 & .169 \\
\hline \multirow[t]{3}{*}{ Model effect ${ }^{\mathrm{c}}$} & $36.27(2)^{* * *}$ & $39.52(3)^{* * *}$ & $107.73(15)^{* * *}$ & $19.83(2)^{* * *}$ & $37.37(3)^{* * *}$ & $102.70(15)^{* * *}$ \\
\hline & \multicolumn{3}{|c|}{ USA Men } & \multicolumn{3}{|c|}{ USA Women } \\
\hline & Model 1 & Model 2 & Model $3^{b}$ & Model 1 & Model 2 & Model $3^{b}$ \\
\hline Income & $1.18(1.12-1.24)^{* * *}$ & $1.17(1.11-1.24)^{* * *}$ & $1.05(0.99-1.12)$ & $1.18(1.13-1.23)^{* * *}$ & $1.18(1.13-1.23)^{* * *}$ & $1.08(1.03-1.12)^{* *}$ \\
\hline Net Worth & $1.09(1.03-1.15)^{* *}$ & $1.08(1.02-1.15)^{*}$ & $1.07(1.01-1.14)^{*}$ & $1.13(1.08-1.18)^{* * *}$ & $1.11(1.07-1.16)^{* * *}$ & $1.10(1.05-1.16)^{* * *}$ \\
\hline Wealth Satisfaction & & $1.02(0.97-1.08)$ & $1.04(0.99-1.10)$ & & $1.06(1.02-1.10)^{* *}$ & $1.09(1.05-1.13) * * *$ \\
\hline Nagelkerke's R ${ }^{2}$ & .102 & .103 & .226 & .140 & .146 & .272 \\
\hline $\mathrm{R}^{2} \Delta$ & & .001 & .123 & & .006 & .126 \\
\hline \multirow[t]{3}{*}{ Model effect ${ }^{\mathrm{c}}$} & $84.57(2)^{* * *}$ & $86.89(3)^{* * *}$ & $190.25(15)^{* * *}$ & $148.68(2)^{* * *}$ & $146.40(3)^{* * *}$ & $423.14(15)^{* * * *}$ \\
\hline & \multicolumn{3}{|c|}{ Korean Men } & \multicolumn{3}{|c|}{ Korean Women } \\
\hline & Model 1 & Model 2 & Model $3^{b}$ & Model 1 & Model 2 & Model $3^{b}$ \\
\hline Income & $1.11(1.08-1.15)^{* * *}$ & $1.07(1.03-1.11)^{* *}$ & $1.01(0.96-1.05)$ & $1.11(1.08-1.15)^{* * *}$ & $1.08(1.04-1.11)^{* * *}$ & $1.03(1.00-1.07)$ \\
\hline Net Worth & $1.09(1.06-1.13)^{* * *}$ & $1.01(0.97-1.05)$ & $1.02(0.97-1.06)$ & $1.11(1.07-1.14)^{* * *}$ & $1.04(1.01-1.08)^{*}$ & $1.02(0.98-1.06)$ \\
\hline Wealth Satisfaction & & $1.31(1.25-1.37)^{* * *}$ & $1.26(1.19-1.33)^{* * *}$ & & $1.27(1.21-1.32)^{* * *}$ & $1.21(1.15-1.29) * * *$ \\
\hline Nagelkerke's R ${ }^{2}$ & .062 & .146 & .355 & .069 & .135 & .325 \\
\hline $\mathrm{R}^{2} \Delta$ & & .084 & .209 & & .066 & .190 \\
\hline Model effect ${ }^{\mathrm{c}}$ & $84.11(2)^{* * *}$ & $179.55(3) * * *$ & $387.94(15)^{* * *}$ & $121.93(2)^{* * *}$ & $231.44(3)^{* * *}$ & $506.96(15)^{* * *}$ \\
\hline
\end{tabular}




\begin{tabular}{|c|c|c|c|c|c|c|}
\hline & \multicolumn{3}{|c|}{ Australian Men } & \multicolumn{3}{|c|}{ Australian Women } \\
\hline & Model 1 & Model 2 & Model $3^{\mathrm{a}}$ & Model 1 & Model 2 & Model $3^{\mathrm{a}}$ \\
\hline Income & $-0.02(0.03)$ & $-0.02(0.03)$ & $-0.02(0.03)$ & $-0.04(0.03)$ & $-0.02(0.02)$ & $-0.02(0.02)$ \\
\hline Net Worth & $0.06(0.03)^{*}$ & $-0.04(0.03)$ & $-0.05(0.03)$ & $0.08(0.03) * *$ & $-0.03(0.02)$ & $-0.04(0.02)$ \\
\hline Wealth Satisfaction & & $0.32(0.04)^{* * *}$ & $0.30(0.04) * * *$ & & $0.37(0.03) * * *$ & $0.36(0.04)^{* * *}$ \\
\hline $\mathrm{R}^{2}$ & .009 & .169 & .217 & .013 & .234 & .272 \\
\hline$\Delta \mathrm{R}^{2}$ & & .160 & .048 & & .221 & .038 \\
\hline \multirow[t]{3}{*}{ Model effect ${ }^{b}$} & $2.37(2,1329)$ & $22.32(3,1328) * * *$ & $8.06(15,1316) * * *$ & $4.78(2.1329)^{* *}$ & $53.17(3,1328) * * *$ & $15.14(15,1316)^{* * *}$ \\
\hline & \multicolumn{3}{|c|}{ USA Men } & \multicolumn{3}{|c|}{ USA Women } \\
\hline & Model 1 & Model 2 & Model $3^{\text {a }}$ & Model 1 & Model 2 & Model $3^{\mathrm{a}}$ \\
\hline Income & $0.04(0.03)$ & $0.03(0.03)$ & $0.03(0.04)$ & $0.05(0.02)^{*}$ & $0.02(0.02)$ & $-0.01(0.03)$ \\
\hline Net Worth & $0.13(0.03) * * *$ & $0.01(0.03)$ & $0.01(0.04)$ & $0.18(0.03) * * *$ & $0.07(0.03)^{*}$ & $0.04(0.03)$ \\
\hline Wealth Satisfaction & & $0.36(0.04)^{* * *}$ & $0.36(0.04)^{* * *}$ & & $0.34(0.03) * * *$ & $0.31(0.03)^{* * *}$ \\
\hline $\mathrm{R}^{2}$ & .025 & .123 & .142 & .044 & .128 & .150 \\
\hline$\Delta \mathrm{R}^{2}$ & & .098 & .019 & & .084 & .022 \\
\hline \multirow[t]{3}{*}{ Model effect ${ }^{b}$} & $13.75(2,1329) * * *$ & $43.76(3,1328) * * *$ & $14.48(15,1316)^{* * *}$ & $35.62(2,1329)^{* * *}$ & $81.59(3,1328)^{* * *}$ & $35.40(15,1316)^{* * *}$ \\
\hline & \multicolumn{3}{|c|}{ Korean Men } & \multicolumn{3}{|c|}{ Korean Women } \\
\hline & Model 1 & Model 2 & Model $3^{\mathrm{a}}$ & Model 1 & Model 2 & Model $3^{\mathrm{a}}$ \\
\hline Income & $0.12(0.02) * * *$ & $0.02(0.01)$ & $0.01(0.01)$ & $0.12(0.02) * * *$ & $0.03(0.01)^{*}$ & $0.03(0.01)^{*}$ \\
\hline Net Worth & $0.21(0.02) * * *$ & $0.03(0.01)^{*}$ & $0.02(0.02)$ & $0.21(0.02) * * *$ & $0.05(0.01)^{* * *}$ & $0.04(0.01)^{* *}$ \\
\hline Wealth Satisfaction & & $0.54(0.03) * * *$ & $0.51(0.03) * * *$ & & $0.53(0.02)^{* * *}$ & $0.50(0.02)^{* * *}$ \\
\hline $\mathrm{R}^{2}$ & .134 & .427 & .452 & .126 & .397 & 0.413 \\
\hline$\Delta \mathrm{R}^{2}$ & & .293 & .025 & & .271 & 0.016 \\
\hline Model effect ${ }^{b}$ & $130.09(2,1329)^{* * *}$ & $343.90(3,1328)^{* * *}$ & $84.76(15,1316) * * *$ & $140.58(2,1329)^{* * *}$ & $444.96(3,1328) * * *$ & $102.17(15,1316)^{* * *}$ \\
\hline
\end{tabular}

